\title{
BIRDWATCHING ETIQUETTE: THE NEED FOR A DEVELOPING PHILOSOPHY
}

\author{
RICHARD L. GLINSKI. Box 17114, Tucson, Arizona 85731
}

EDITOR'S NOTE: This article has been condensed from the June, 1976, issue of American Birds. It refers to birdwatching in the United States but applies equally to Canada, particularly to well known, favourite birding areas and to threatened species.

Birdwatching is a relatively recent leisure-time activity that involves interactions between man and birds that range from casual observation at window feeders to ardent 'life-listing' and photography. Its popularity as a sport has grown immeasurably in the last decade, and an ever-increasing number of unique canyons and shorelines are being preserved partly in recognition of the nongame birdlife they harbor. .

In April of 1975 the U.S. Forest Service co-sponsored a symposium that dealt with the management of forest and range habitats for nongame birds.' The underlying reason for assembling experts in fields related to nongame ornithology was the new awareness of the value of the nonhunted-bird resource and of the need to manage its habitat.

Thus far there has been little mention of the effects of birdwatchers on the habitat and productivity of their quarry. The term management as it applies to nongame species is often viewed as either the preservation or manipulation of habitats; little attention is given to the management of people. .

The intents of this essay are to oresent specific examples that indicate the need to manage birdwatchers, to propose the foundations of a pehavioral code, an etiquette, that will egulate birdwatching activities on a pesonal and individual basis, and to generate further thought and study of the impact of man's seemingly harmless associations with nongame birds.... .

Various techniques are employed to locate a particular species, including well organized groups that are led by knowledgeable guides, solitary or paired birders that stalk quietly and slowly, and disorganized groups and individuals that stumble loudly and randomly about. One common method of attracting a specific bird is to play taped recordings of that species' territorial vocalizations, which often readily lures the desired bird to the 'trespasser' in a fury of defensive displaying and calling. The nesting territories of many small birds and the exact nest tree of some raptors become well known - even published - and are often visited to insure sighting or photographing the residents.

Taped vocalizations played at various times of the day probably disrupt the circadian rhythms that dictate the performance of territorial calling and displaying during certain times of the day, such as during the cool early morning hours in hot desert climates. Abnormal responses of small birds may make them or their unguarded nestlings more susceptible to predation. Tape recordings also frequently distract - and attract other birdwatchers and can ruin the pleasant surroundings of natural bird song .

Visits to active raptor nests usually result in an unfortunate waste of energy by the adult hawks that fly around the nest tree and call at the intruders. If such disturbances occur early in the breeding cycle, the pair 
may abandon that nest. If renesting occurs, fledging success may be reduced since the timing of the breeding cycle was altered. Large birds generally nest only once during a breeding season, and their activities from nest-building through postfledging attendance can last up to five months or even longer for eagles.

The timing of this cycle with other yearly cycles of temperature, rainfall and prey abundance is critical, thus large peripheral species cannot tolerate nesting disruptions. Moreover, eggs that are left unattended while the adult birds are warding off intruders are vulnerable to chilling and... to overheating when they are exposed to midday sunshine.

Amateur photographers tend to linger obtrusively in certain areas where a particular species is known to reside, and they may cause wary birds to abandon that site. Federal regulation now prohibits photographing species that are legally classified as "endangered." Hiking trails that approach breeding sites of endangered wildlife are being closed during the spring and summer while reproduction occurs. Much of the avifauna of North America has not been sufficiently investigated, and many birds that may presently merit legal "endangered" distinction are excluded from the official list simply because there are no data to justify their inclusion.

In delicate habitats, abandonment of nests may be the indirect result of vegetation destruction caused by the trampling of too many people.

Dead tree trunks and snags that shelter cavity-nesting birds can be knocked over by incessant tapping that shakes the occupants from the hole for all to see.

Essentially, the effects of birdwatching are unknown; it has been assumed that to pursue birds with binoculars is inconsequential. The impacts of such pursuit no doubt vary with the species observed and the time and location of the observation: thousands of birders were able to witness with a minimum of disturbance a wintering Ross' gull as it fed along a coastal shore in Massachusetts, yet a small fraction of the many people along Sonoita Creek during the nesting season of the Fivestriped Sparrow could diminish the reproductive capability of this species in Arizona and the United States.

Unlike the interaction between man and game animals, which is regulated with data supplied by the established science of wildlife management, the recreational interaction between man and nongame species, especially birds, is neither understood nor managed. Proper wildlif,e management techniques dictate the gamebirds are not to be hunted with a shotgun during the breeding season. Similarly, nongame birds that are actively nesting should not be subjected to the uncalculated pressures of unregulated birdwatching.

The management of people who birdwatch, especially those who visit unique habitats during the nesting season, is a procedure that inevitably will be effected to preserve specific rare birds and their haunts. The methods of governing people generally involve limiting the access to designated areas during certain times of the year. If such procedures are handled carefully, the attractive atmosphere and impressive experiences of favorite birding places can be maintained without the artificialness that is normally associated with management. But regulation of this sort requires supporting data, which is lacking; furthermore, it demands money and a vast amount of human energy to sustain the regulatory bureaucracy.

One way to provide an efficient base from which the sport of bird watching can continue, to improve the quality of the sport and its par. ticipants, to minimize disturbances to exceptional habitats and rare birds and to reduce the need for costly bureaucratic control of birders is tc adopt an etiquette that prescribe: general good manners for bird watchers. The value of such 


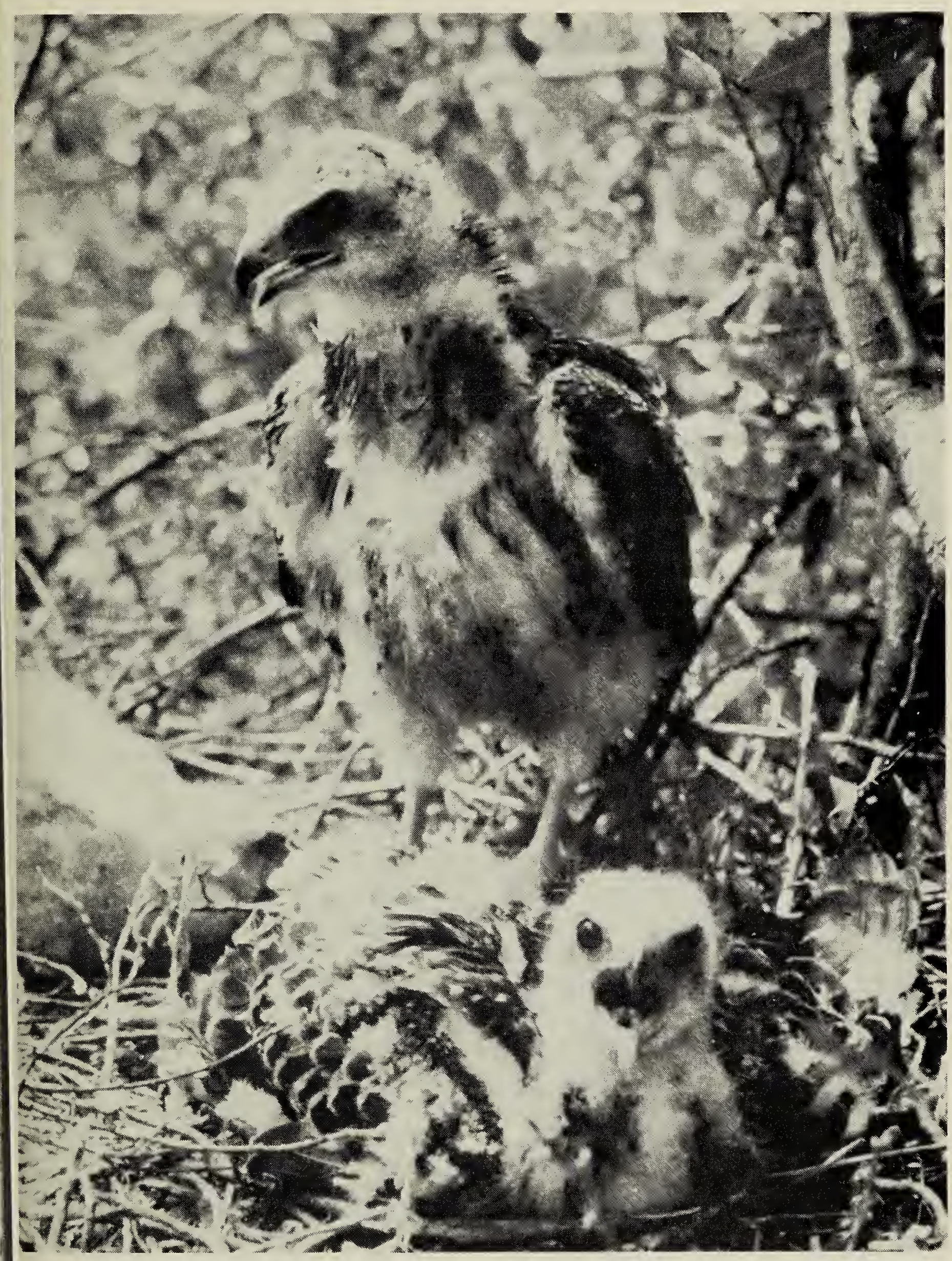

Young Swainson's Hawks

Gary Anweiler

behavioral code is evident in the fact that the traditional manners of social etiquette usually facilitate the activities and interactions of those who conform to its rules by prescribing the behaviors which have proven to be the most efficient way for people to interact collectively. The ethical conduct of the individual is the basis for proficient behavior on any level of human interaction. 
Any attempt to prescribe a birdwatcher's behavior should treat those activities that are performed in critical habitats, with raptors or rare birds, or during the nesting season. The occurrence of the nesting season and the relative scarcity of certain birds are generally known. Although critical habitats are not defined for many species, here they will be considered as small, isolated or unusual habitats that are favorite birdwatching locations.

I offer the following comments as a start toward what hopefully will be a developing etiquette. They are designed to provide an efficient means of birdwatching, whereby efficiency is gauged in terms of the number of birds seen per unit of birdwatcher-energy expended in memorable surroundings, and in terms of the number of fledglings produced in a specific area despite the presence of birders. They are presented simply as a foundation, and hopefully as a stimulus for further thought and research on the impacts of birdwatching.

1) Avoid the use of tape-recorded territorial calls of rare birds that are actively breeding. Universal attractants such as "pishing" are more acceptable since they probably have fewer adverse effects than the use of specific calls.

2) Observe bird nests from a distance great enough so that parent birds and their activities are not disturbed. Nesting colonies and raptor nests should be avoided.

3) Do not relentlessly follow or harass rare birds. Photography of birds should never include 'the removal of nestlings from the nest or of foliage close to the nest.

4) Respect the property and wishes of the private landowner. Many of the best birding places are on deeded lands, where the misbehavior of one can result in the exclusion of all.

5) Do not associate with large groups that are bused en masse to critical habitats and then turned loose without responsible guides. A responsible guide is one who: (a) knows the status of the species and the habitat in the area he is touring; (b) knows the most efficient way to view the avifauna with a minimum of disturbance; (c) limits the size of his group, thus enabling himself to convey effectively not just the markings on birds, but also the known individual traits and ecological requirements of each species. Do associate with responsible guides that offer more than a mere tally of field marks.

Although this beginning etiquette is mainly an aggregate of "do nots" that restrict one's activities, everyone can still boundlessly explore new methods of birding that will preserve both the sport and the resource. Doubtless there are many critical habitats that need to be recognized as such, and birders who realize this need in their area should inform visiting birders about the local problems and discover new ways of harmlessly viewing the threatened avifauna. Critical habitats of threatened species should be posted as such, preferably under the sponsorship of the local chapter of the National Audubon Society or conservation organization.

In conclusion, the effectiveness of the preceding discussion rests on the performance of the individual. While a society can accept the manners of an etiquette, the individual must possess a sense of propriety if the collective effort is to succeed. There can be no room for the over-zealous listers who are oblivious of everything but a field mark, and who unknowingly may run over a nest while attempting to see the "white bar on the wings." These people take from the sport of birding much more than they are able to give, for they can never develop a concern for birdlife as quickly as they can collect check-marks on a field list.

'SMITH, D. R., technical coordinator. 1975. Proceedings of the symposium of management of forest and range habitats for nongame birds. (May 6-9, 1975, Tucson, Ariz.) USDA For. Serv. Gen. Tech. Rep. WO-1, 343p. Wash., D.C. 